\title{
Development of Subjective Well-Being Increasing Strategies Scale for Children (1-5 Ages) Their Mothers Use
}

\author{
Ali Eryılmaz ${ }^{1}$ Özkan Sapsağlam ${ }^{1}$ \\ ${ }^{1}$ Faculty of Education, Yildiz Technical, Istanbul, Turkey \\ Correspondence: Özkan Sapsağlam, Faculty of Education, Yildiz Technical, Istanbul, Turkey.
}

Received: March 25, 2018

Accepted: April 18, 2018

Online Published: April 23, 2018

doi:10.11114/jets.v6i6.3125

URL: https://doi.org/10.11114/jets.v6i6.3125

\begin{abstract}
Subjective well-being is a sign of positive mental health of children. The aim of the present study is to develop subjective well-being increasing strategies scale for children whose mothers' uses are varied 1 to 5 . In this study, there were 195 mothers whose mean ages were 31, 49 and standard deviation were 4,71. Satisfaction with life, positive and negative affect scales were used. Moreover, item analysis, exploratory factor analysis, reliability and validity analysis were used. According to results, the scale has $66,03 \%$ explained variance and four dimensions which were named as acting physical contact, playing game, satisfaction of desires and take out. The reliability and validity of the scale have enough values. The scale is valid and reliable. In future, some researches might carry out with this scale in order to increase children's' physical and mental health.
\end{abstract}

Keywords: scale, well-being, strategies, children

\section{Introduction}

As important in human life, one of the important issues in psychology is happiness. In psychology, happiness is treated by the concept of subjective well-being as people have positive emotions frequently, experience negative emotions few and have satisfaction from their lives. Subjective well-being is an important indicator in terms of both mental and physical health. (Diener, 1984; Lyubomirsky, Sheldon ve Schkade, 2005). In other words, as the subjective well-being of individuals increases, their physical and mental health have also been found to be in a more positive position. Subjective well-being is also important in infancy and early childhood as it is in other stages of life. Increasing the subjective well-being of babies and children can bring their mental and physical health to a more positive level. It can be functional in many ways to work on subjective well-being increasing strategies, which are tools to bring individuals' subjective well-being to a more positive level. Thus, scientific findings can be revealed both for the subjective well-being of children and for parenting practices and also for mental health professionals offer more qualified psychological and psychiatric support.

Positive emotions, negative emotions and life satisfaction are seen also important components in the subjective well-being of children. Children with high levels of subjective well-being have been found associated with showing less psychopathological symptoms, being more resilient and exhibit a positive development patterns (Casas, 2011). These results suggest that the level of subjective well-being of children should be raised.

The issue of raising children's subjective well-being is addressed mostly in the context of subjective well-being increasing strategies (Eryllmaz, 2010). The first studies on subjective well-being increasing strategies in the literature have been published by Fordyce (1983). Fordyce (1983) has developed effective strategies such as optimistic thinking, having an active life, improving the ability to be an outward individual, and reducing negative thoughts. Evolutionary psychologist Buss (2000) has also addressed subjective well-being increasing strategies on the basis of evolutionary psychology. He has set out strategies based on the adaptation of individuals of their lives such as establishing relationships with relatives, reducing subjective stress, transforming competitive structures into cooperation, and satisfying their desires.

Tkach and Lyubomisrsky (2006) has carried out studies on the subjective well-being increasing strategies. According to them, strategies such as being in social relations, satisfying the desires, performing mental control, exhibiting behaviors towards direct happiness, being in active and passive activities, determining goals are strategies for increasing the subjective well-being of individuals. In Turkey, Eryllmaz (2010), studied subjective well-being increasing strategies on 
adolescents. According to him, there are five important strategies used by adolescents, such as reacting positively to the environment, getting positive reactions from the environment, satisfying the desires, performing mental control, and doing requirements of the religious belief. Eryllmaz (2014) examined the subjective well-being increasing strategies for adults using by experience sampling method. According to the results of the research, it was found that the adults used the strategies such as satisfying the desires, being in positive relations with the environment, performing mental control, showing behavior towards direct happiness and doing requirements of the religious belief.

There are many factors that are effective in the subjective well-being of children. One of these factors are also their families. The family is the place where basic knowledge and skills are learned and the main source that children fed (Sapsağlam and Ömeroğlu, 2015). Estanblishing positive relationships with parents affects psychological well-being of individual (Amato, 1994) to show a positive development (Pulkkinen, Nygren and Kokko, 2002) to demonstrate their potentials (Ryan and Deci, 2001) in both short-term and long-term. In the literature, there are studies on the subjective well-being of children and their parents that they are addressed together. These studies are based on the fact that subjective well-being is influenced by genetic susceptibility (Lykken and Tellegen, 1996). For example, Casas et al. (2008) found low and positive relationships in subjective well-being of children and their parents that were addressed together in their studies. Similarly, Cummins and colleagues (2003) found a low level correlation in their studies.

Children and parents are examined in terms of their subjective well-being, not examined in terms of subjective well-being increasing strategies. In addition, children aged between 12 and 16 years and their parents are usually studied in these studies. Children in this age group have significantly improved self-care skills, cognitive skills and social skills compared to infants and children in the first childhood (Santrock, 2012). In other words, individuals in these working groups are more active than passive in terms of subjective well-being. Children aged one to five years are both more passive in terms of increasing their subjective well-being and more affected by positive-negative interactions within the family (because defensive mechanisms are not developed) (Patterson, 1992). In conclusion, evaluation of children aged 1-5 years in terms of strategies for increasing subjective well-being seems more functional through their parents.

When the studies discussed above are examined, it can be seen that these studies are carried out on either adults or young adults or adolescents. On the other hand, the subjective well-being of children also needs to be increased. Studies have shown that subjective well-being of children up to the age of 7 can be measured (Casas, 2011). According to Eryllmaz (2014), children aged 0-6 are in a passive position to raise their subjective well-being. More often, the parents of children play a role in increasing their subjective well-being. Besides, studies that measure the subjective well-being of children are found in the literature (Cummins et al., 2003); it is possible to see that the measurement tools that can measure the strategies used by parents to increase their children's subjective well-being have not yet been developed. In conclusion, this study aimed to develop a measurement tool that can measure the subjective well-being increasing strategies used by mothers of children aged 1 to 5 years.

\section{Method}

The aim of this study is to develop a measurement tool that can be used by parents of children aged 1 and 5 years to improve their subjective well-being strategies for their children. The study was carried out in cross-sectional research design and the stages of scale development in the study were monitored. In the context of scale development; it was performed a study as the formation of scale items and trial form, exploratory factor analysis, item analysis, reliability analysis based on internal consistency and validity. The data in the study was collected as individual applications. Ethical principles were considered in the study and data were collected on the basis of volunteerism. In the validity study, subjective well-being of the mothers was assessed. At this point, the calculation of subjective well-being was made use of the following form:

Subjective well-being $=$ (positive feeling + life satisfaction $)$ - negative feeling .

\subsection{Preparation of Materials}

Several ways were followed in the preparation of the materials. The first of these, the literature on subjective well-being and subjective well-being increasing strategies is examined (Eryilmaz, 2010; Tkach and Lyubomirsky, 2006). As a second method; mothers of children between 1 and 5 years of age were interviewed. In this direction, an open-ended question was asked, "What do you do for your child's good feeling (happy)?" to 10 mothers in every age group of children in interview. Sentence-based content analysis was applied to the answers given to the questions. As a result of the study, it has been shown that the sentences were collected in four dimensions. The most frequently expressed sentences are put into the scale preliminary test form. Thus, a 20-item scale test form has been reached. It has been examined in terms of form, expression and as to whether it is a participation indicator for specialists with a doctorate degree in educational psychology and measurement fields. It was decided that the 3 items in the test form should be removed from the scale and the 2 items should be corrected in terms of language and semantic information. As a result, it has been decided that 17 items remained in the test form and studies have been done through this form. 


\subsection{Participants}

The individuals involved in this study were mothers of children aged between 1 and 5 years. The study included 195 participants between the ages of 20 and 44 (mean $=31.49$, standard deviation $=4.71)$. 33 of the mothers in the study are graduated from primary education (16.9\%), 70 from high school (35.9\%) and 92 from college (47\%). 116 were housewives (59.5\%), 69 were civil servants $(35.4 \%)$ and 10 were workers $(5.1 \%)$. In study, 96 mothers have daughter $(49.24 \%)$ and 99 mothers $(50.76 \%)$ have male children. Distribution of the mothers according to ages of their children in the study; 1 year old 58 children (29.7), 2 years old 54 children $(27.7 \%), 3$ years old 17 children $(8.7 \%)$, 4 years old 27 children $(13.8 \%)$ and 5 years old 39 children $(20 \%)$.

\subsection{Data Collection Tools}

In the study, the positive and negative effects and life satisfaction of the mothers were measured to examine the validity of the developed scale. For this purpose, Positive and Negative Affect Schedule and Satisfaction with Life Scale were used.

Satisfaction with Life Scale: This scale was developed by Diener Diener (1994). The Turkish adaptation of the scale was carried out by Yetim (1993). There are a total of 5 items on the scale. The scale is 7-point Likert type. The scale of life satisfaction measures whether or not individuals are satisfied with their lives. Life satisfaction is a cognitive component of subjective well-being. The scale measures individuals' satisfaction from their lives. In the adaptation study of the scale, the reliability coefficient based on the two halves was calculated as 0.75 and the value of Kuder Richardson-20 as 0.79 .

Positive-Negative Affect Scale: The Positive-Negative Affect Scale was developed by Watson et al. (1988). The scale contains ten positive and ten negative emotions. It is 5-point Likert type. It is intended to determine how often individuals experience positive and negative emotions. Gençöz (2000) adapted this scale to Turkish. In the adaptation study, reliability analysis studies based on internal consistency of the scales were carried out. According to this, the internal consistency value for positive affection dimension is 0.88 . For negative affect, the internal consistency value is 0.87 .

\section{Results}

\subsection{Item Analysis}

In this study, an item analysis study was conducted to determine the items to be included in the developed scale. The item analysis study was conducted on the upper and lower $27 \%$ groups. In order to carry out item analysis, t-test technique for independent groups was used. In addition to all these, item-total correlations have also been examined (Çokluk, Şekercioğlu \& Büyüköztürk, 2010). According to the results, in terms of item-total correlations, 4. Items were found to have a value less than 0.30 . This item has been removed. Correlations of the remaining items with total points range from 0.45 to 0.71 . In addition, it was seen that the high and low points were very well distinguished in the comparison of the upper and lower $27 \%$ groups (each group has 52 participants). The results at this point are given in Table 1. 
Table 1. Results of Item Analysis

\begin{tabular}{|c|c|c|c|c|c|}
\hline Items & Group & $\mathrm{N}$ & $\mathrm{M}$ & $\mathrm{Sd}$ & t-values \\
\hline \multirow[t]{2}{*}{1} & Lower & 52 & 2,69 & ,61 & $-6,74 * *$ \\
\hline & Upper & 52 & 3,50 & 61 & \\
\hline \multirow[t]{2}{*}{2} & Lower & 52 & 1,96 & ,79 & $-10,37 * *$ \\
\hline & Upper & 52 & 3,48 & 69 & \\
\hline \multirow[t]{2}{*}{3} & Lower & 52 & 1,76 &, 78 & $-7,49 * *$ \\
\hline & Upper & 52 & 2,96 &, 83 & \\
\hline \multirow[t]{2}{*}{5} & Lower & 52 & 2,69 &, 78 & $-8,32 * *$ \\
\hline & Upper & 52 & 3,75 &, 47 & \\
\hline \multirow[t]{2}{*}{6} & Lower & 52 & 2,42 & ,93 & $-6,76^{* *}$ \\
\hline & Upper & 52 & 3,51 & 69 & \\
\hline \multirow[t]{2}{*}{7} & Lower & 52 & 1,96 & ,96 & $-5,30 * *$ \\
\hline & Upper & 52 & 2,94 & ,91 & \\
\hline \multirow[t]{2}{*}{8} & Lower & 52 & 2,48 & 1,05 & $-6,82 * *$ \\
\hline & Upper & 52 & 3,61 &, 56 & \\
\hline \multirow[t]{2}{*}{9} & Lower & 52 & 3,34 &, 68 & $-4,97 * *$ \\
\hline & Upper & 52 & 3,88 &, 37 & \\
\hline \multirow[t]{2}{*}{10} & Lower & 52 & 1,73 &, 95 & $-5,67 * *$ \\
\hline & Upper & 52 & 2,88 & 1,11 & \\
\hline \multirow[t]{2}{*}{11} & Lower & 52 & 2,80 &, 95 & $-6,32 * *$ \\
\hline & Upper & 52 & 3,76 &, 54 & \\
\hline \multirow[t]{2}{*}{12} & Lower & 52 & 2,36 & 1,15 & $-5,85^{* *}$ \\
\hline & Upper & 52 & 3,51 &, 82 & \\
\hline \multirow[t]{2}{*}{13} & Lower & 52 & 2,38 & 1,06 & $-8,11 * *$ \\
\hline & Upper & 52 & 3,71 &, 49 & \\
\hline \multirow[t]{2}{*}{14} & Lower & 52 & 1,92 &, 81 & $-9,09 * *$ \\
\hline & Upper & 52 & 3,32 &, 75 & \\
\hline \multirow[t]{2}{*}{15} & Lower & 52 & 3,46 &, 57 & $-6,74 * *$ \\
\hline & Upper & 52 & 4,00 &, 00 & \\
\hline \multirow[t]{2}{*}{16} & Lower & 52 & 3,61 &, 49 & $-4,06^{* *}$ \\
\hline & Upper & 52 & 3,94 &, 30 & \\
\hline \multirow[t]{2}{*}{17} & Lower & 52 & 3,55 &, 57 & $-5,55^{* *}$ \\
\hline & Upper & 52 & 4,00 &, 00 & \\
\hline
\end{tabular}

$* \mathrm{p}>0.05 ; * * \mathrm{p}>0 . \overline{01}$

\subsection{Factor Structure of the Developed Scale}

In order to determine the factor structure of the developed scale, an exploratory factor analysis study was carried out. At this point, exploratory factor analysis has been carried out in the direction of Principal Components Analysis. In the study, Kaiser-Meyer-Olkin (KMO) coefficient and Barlett test value were examined. According to the analysis results, KMO value was found as 0.822 ( $\mathrm{p}<.01$ ) and Barlett`s Test of Sphercity Ki Square value was found as 779, 771 (p <.01). These results show that the sample size is adequate (depending on the value of KMO) and that the sample meets the assumption of multivariable normality (depending on the Barlett test results) (Çokluk, Güçlü and Büyüköztürk, 2014).

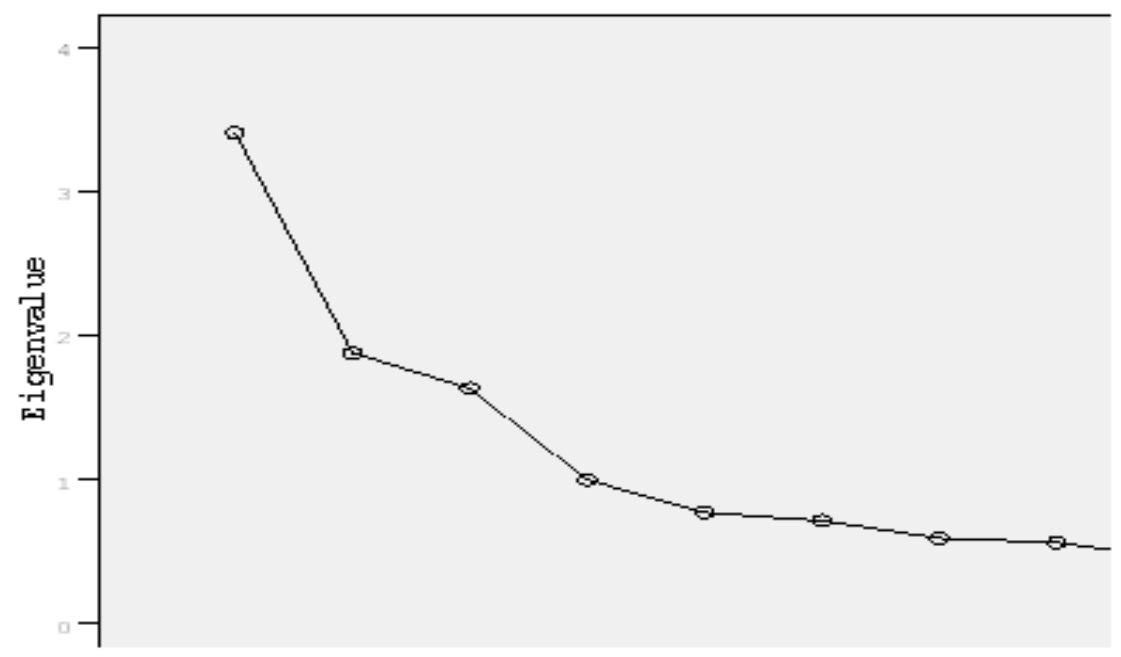

Figure 1. Scatter Diagram 
Table 2. Results of Exploratory Factor Analysis

\begin{tabular}{ccccc}
\hline & \multicolumn{4}{c}{ Dimensions } \\
\hline 16 & 1 & 2 & 3 & 4 \\
17 &, 891 & & & \\
15 &, 852 & & & \\
6 &, 825 & & & \\
5 & &, 828 & & \\
8 & &, 727 & & \\
13 & &, 706 &, 815 & \\
12 & & &, 721 & \\
14 & & &, 615 &, 878 \\
1 & & & &, 656 \\
2 & & & & 13.98 \\
3 & 19.60 & 16.86 & 15.57 & 1.67 \\
\hline Explained Variation & 2.35 & 2.02 & 1.86 & 15 \\
\hline Eigenvalue & & & & \\
\hline
\end{tabular}

In this study, the assumption is that the factors may be related to each other. In this direction, Varimax Rotation technique was used in the exploratory factor analysis in the study. At the beginning of the analysis, four items with factor loadings of less than 0.30 and related more than one factor at the same time were excluded from the analysis. As a result, a four-dimensional scale with a variance of $66.03 \%$ was achieved. According to the results of the analysis, the factor loadings of the items vary between 0,61 and 0,89 . The dimensions of the scales were named by looking at the analysis results and the structures of the items. At this point, the first dimension of the scale is named as "having physical contact with the child", the second dimension is "playing with the child", the third dimension is "satisfying the child's desires" and the fourth dimension is "taking the child out".

\subsection{The Reliability of the Subjective Well-Being Increasing Strategies Scale for Children (1-5 Ages) Their Mothers Use}

The reliability of the Subjective Well-Being Increasing Strategies Scale for children whose mothers use (1-5 ages) is determined by the Cronbach Alfa internal consistency technique. According to this, the alpha value of the dimension of having physical contact with the child is 0.85 ; the alpha value of the dimension of playing with the child is 0.70 ; the alpha value of the dimension of satisfying the child's desires was 0.63 , and the alpha value of the dimension of taking child out was 0.61 . The alpha value of the complete scale was 0.72 . Based on these results, it can be stated that the developed scale is a reliable scale (Çokluk, Güçlü and Büyüköztürk, 2014).

\subsection{The Validity of the of Subjective Well-Being Increasing Strategies Scale for Children (1-5 ages) Their Mothers Use}

The validity of the Subjective Well-being Increasing Strategies Scale for children whose mothers use (1-5 ages) was examined by the Pearson Product-Moment Correlation coefficient between the scores of subjective well-being of the mothers and the scores of the developed scale. The results are shown in Table 3. When the results are examined, it is seen that higher levels of subjective well-being mothers use more strategies for their children.

Table 3. Results of Validity Analysis

\begin{tabular}{|c|c|c|c|c|c|c|}
\hline Dimensions & 1 & 2 & 3 & 4 & 5 & 6 \\
\hline 1. Subjective Well-being & 1 & & & & & \\
\hline Physical Contact &, $19 * *$ & 1 & & & & \\
\hline Playing with Children & $16^{*}$ &, $30 * *$ & 1 & & & \\
\hline 4. Satisfying Desires & $10 *$ & $24 * *$ & 040 & 1 & & \\
\hline 5. Take Out & $23 * *$ & $20 * *$ & $29 * *$ &, $39 * *$ & 1 & \\
\hline 6. Total Score of the Scale &, $25 * *$ &, $53 * *$ &, $63 * *$ &, $68 * *$ &, $74 * *$ & 1 \\
\hline
\end{tabular}

\section{Discussion}

In this study, a scale was developed for children aged between 1 and 5 years that can measure strategies of their mothers' for increasing their subjective well-being. According to the results of the study, the mothers have children between the ages of 1-5 brought their subjective well-being to a more positive level with four important strategies: physical contact, playing games with them, satisfying children's desires and taking their children out. The results of the study were evaluated in accordance of the literature.

According to Vaillant (2003) subjective well-being represents the positive side of mental health. There are studies that focus on the subjective well-being of middle-aged children and adolescents in the literature (Eryllmaz, 2010, 2014). It seems that there is no scale development work on subjective well-being increasing strategies for kids and infants. At this point it can be said that this study contributes to the literature.

Subjective well-being is important for the individual at every stage of life. Studies of subjective well-being are more 
likely to be addressed during middle childhood and adolescence (Casas, 2011; Casas et al., 2008; Patterson, 1992). It is also seen that studies examining the subjective well-being of infants and kids are also carried out. For example, Parkes, Sweeting, and Wight (2016) have longitudinally examined the subjective well-being of 10-month-olds up to 70 months of age. The results of the study showed that parents and family structure had effects on children's subjective well-being. These findings indicate that the family should participate in the study on subjective well-being in infancy and early childhood. In this study also, mothers were included as parents. In this respect, this study showed a pattern parallel to the literature.

In this study, one of the strategies that mothers used for their children's subjective well-being was found as physical contact. It is a very interesting finding that physical contact with children is a subjective well-being increasing strategy. Physical contact has been found to facilitate development and growth for both people and animal species (Ardiel and Rankin, 2010). From a psychological point of view, physical contact has a vital prescription to form attachment patterns. According to Hendrick (2003), attachment occurs through consistency in interaction, stability, and physical contact. In addition, attachment is a lifelong process (Cassidy, 1999). In addition to all of these, researches have shown that physical contact is effective in the secretion of endorphin hormones (Hefferon and Boniwell, 2011). As a result, physical contact is seen as a positive factor influencing individuals' happiness and well-being. Because of the mentioned characteristics of physical contact, it can be thought that it emerged as a strategy for increasing subjective well-being.

Another dimension of the scale developed in this study is seen as playing games with children. When we look at psychology literature; it is stated that the game has significant effects on the cognitive, social and physical development of the individual (Vygotsky, 1967). So much so that play is seen as a child's work. The game is also used as a therapy method because of its positive features. It is also stated that the game is an important tool in improving the well-being of children (Ergler, Kearns and Witten, 2013). Because of the mentioned positive characteristics of the game, it can be concluded that it is an important strategy for increasing the subjective well-being of children in this study.

In this study, satisfying the desires was found to be an important strategy for children. At this point, studies on adults and adolescents in particular have revealed that satisfying the desires is an important strategy to increase subjective well-being (Buss, 2000; Eryılmaz, 2010). The fact that a strategy of satisfying the wishes for children shows that it is a common strategy for the individuals in all developmental periods. This may be due to the fact that the strategy of satisfying the desires has more of a biological continuity characteristic. People have to maintain their physical presence until birth to death. At this point, it can be said that the strategy of satisfying desires serves as an important mediator.

In this study, a strategy to take the child out has also come in sight. There is no study in the literature that shows the relationship between going on an outing of children and subjective well-being. Going on an outing of children may give rise to have stimulation and exploration to them in many ways. Having discovery and stimulation may have mediated to children feel good about themselves.

In this study, a scale of subjective well-being strategies used by mothers of children aged 1-5 years was developed. With the developed scale, studies can be made that address the relationship between children's physical and mental health. It is also possible to utilize the strategies set out in this study to increase the subjective well-being of unhappy children.

\section{References}

Amato, P. R. (1994). Father-child relations, mother-child relations, and offspring psychological well-being in early adulthood. Journal of Marriage and the Family, 1031-1042.

Ardiel, E. L., \& Rankin, C. H. (2010). The importance of touch in development. Paediatrics \& Child Health, 15(3), 153-156.

Buss, D. M. (2000). The evolution of happiness. Am. Psychol., 55, 15-23.

Casas F. (2011). Subjective social indicators and child and adolescent well-being. Child Indicators Research, 4(4), 555-575.

Casas, F., Coenders, G., Cummins, R. A., Gonza`lez, M., Figuer, C., \& Malo, S. (2008). Does subjective well-being show a relationship between parents and their children? Journal of Happiness Studies, 9 (2), 197-205.

Cassidy, J. (1999). Handbook of attachment: Theory, research, and clinical applications. London: Rough Guides.

Çokluk, Ö., Güçlü, Ş., \& Büyüköztürk, Ş. (2014). Sosyal bilimler için çok değişkenli istatistik: SPSS ve LISREL Uygulamaları. Ankara: Pegem Akademi.

Cummins, R. A., Eckersly, L., Pllant, J., Vugt, V., \& Misajon, R. (2003). Developing a national index of subjective wellbeing: The Australian Unity Wellbeing Index. Social Indicators Research, 64(2), 159-190.

Diener, E. (1984). Subjective well being. Psychol Bull, 95, 542-575. 
Diener, E. (1994). Assessing subjective well-being: Progress and opportunities. Social Indicators Research, 31(2), 103-157.

Ergler, C. R., Kearns, R. A., \& Witten K. (2013). Seasonal and locational variations in children's play: Implications for wellbeing. Social Science \& Medicine, 91, 178-185.

Eryılmaz, A. (2010). Ergenler için öznel iyi oluşu artırma stratejileri ölçeğinin geliştirilmesi. Türk Psikolojik Danışma ve Rehberlik Dergisi, 33, 81-88.

Eryılmaz, A. (2012). A model of subjective well-being for adolescents in high school. Journal of Happiness Studies, 13(2), 275-289.

Eryılmaz, A. (2014). Strategies adopted by Turkish adults for increasing happiness in daily life. Mental Health, Religion \& Culture, 17(7), 680-689.

Fordyce, M. W. (1983). A program to increase happiness: further studies. J Couns Psychol, 30, 483-498.

Gençöz, T. (2000). Positive and negative affect schedule: A study of validity and reliability. Turkish Journal of Psychology, 46, 19-26.

Hefferon, K., \& Boniwell, I. (2011). Positive psychology: Theory, research and applications. London: Mcgraw-Hill.

Hendirick, S. S. (2003). Understanding close relationships. London: Allyn \& Bacon.

Lykken, D., \& Tellegen, A. (1996). Happiness is a stochastic phenomenon. Psychol, 7, 186-189.

Lyubomirsky, S., Sheldon, K. M., \& Schkade, D. (2005). Pursuing happiness: The architecture of sustainable change. Rev Gen Psychol, 9, 111-131.

Parkes, A., Sweeting, H., \& Wight, D. (2016). Early childhood precursors and school age correlates of different internalising problem trajectories among young children. Journal Of Abnormal Child Psychology, 44(7), 1333-1346.

Patterson, J. M. (1992). Promoting resilience in families experiencing stress. Pediatric Clinics of North America, 42, 47-63.

Pulkkinen, L., Nygren, H., \& Kokko, K. (2002). Successful development: Childhood antecedents of adaptive psychosocial functioning in adulthood. Journal of Adult Development, 9(4), 251-265.

Ryan, R., \& Deci, E. L. (2001). On happiness and human potentials: A review of research on hedonic and eudaimonic well-being. Annual Review Of Psychology, 52(1), 141-166.

Santrock, J. W. (2012). Life-Span Development. New York: McGraw Hill Companies.

Sapsağlam, Ö., \& Ömeroğlu, E. (2015). Okul öncesi öğretmenlerinin eğitim programlarında değerler eğitimine yer verme düzeylerinin belirlenmesi. International Journal Of Eurasia Social Sciences, 6(21), 244-264.

Tkach, C., \& Lyubomirsky, S. (2006). How do people pursue happiness, relating personality, happiness-increasing srategies, and wellbeing? J Happiness Stud., 7, 183-225.

Vaillant, G. E. (2003). Mental health. Am J Psychiatry, 160, 1373-1384.

Vygotsky, L. S. (1967). Play and its role in the mental development of the child. Soviet Psychology, 5(3), 6-18.

Watson, D., Clark, L. A., \& Tellegen, A. (1988). Development and validation of brief measures of positive and negative affect: the PANAS scales. Journal of Personality and Social Psychology, 54 (6), 1063-1070.

Yetim, Ü. (1993). Life satisfaction: A study based on the organization of personal projects. Social Indicators Research, 29(3), 277-289.

\section{Copyrights}

Copyright for this article is retained by the author(s), with first publication rights granted to the journal.

This is an open-access article distributed under the terms and conditions of the Creative Commons Attribution license which permits unrestricted use, distribution, and reproduction in any medium, provided the original work is properly cited. 